\title{
PLC Control System for Translation Motion Stereo-garage
}

\author{
Libo Wang ${ }^{1,}$, , Lin Lin ${ }^{2, b}$ \\ ${ }^{1}$ Sichuan Aerospace College of Vocational Technology, Chengdu Sichuan 610100, China \\ ${ }^{2}$ Chengdu Aeronautic Polytechnic, Chengdu Sichuan 610100, China \\ a6549651@qq.com, bnarcia@163.com
}

\begin{abstract}
Keywords: Stacker translation stereo-garage; PLC Control System; Queuing Theory.
Abstract. A PLC (Programmable Logic Controller) control system for a stacker translation stereo-garage is presented in this paper. Firstly, the overall scheme of the stacker translation stereo-garage is proposed according to user requirement, and the structure scheme and automatic parking and taking flow of a vehicle are introduced in detail, especially the Queuing Theory is used to optimize the automatic control process. And then, based on the analysis on the technological requirements of the stacker translation stereo-garage, its PLC control system scheme is proposed. The proposed control system for stacker translation stereo-garage has simplicity of operator, and can realize full automatic control. The control system had used in the actual three-dimensional garage control, and good effects had been obtained.
\end{abstract}

\section{Introduction}

With the improvement of living standards, cars come into our daily life rapidly. So parking comes to be a serious issue of urban traffic. In order to effectively use land resources and solve this problem, the multilayer three-dimensional garages have rapidly been developed toward the air and underground [1-4]. According to different circulation way to access a vehicle, the stereo garages could be divided into the several types, such as vertical lifting, vertical circulating, lifting and transferring, and stacker translation, etc. [4]. A qualified stereo garage it is necessary to access a vehicle with not only high safety and reliability but also high efficiency to reduce waiting time during the peak of accessing vehicles. And it is important to ensure not only the structural safety by mechanical optimization design theory and method but also the safe operation of the control system by selecting a controller with high reliability and an appropriate safety control strategy. At present the controllers, which is common used in the control system for a three-dimensional garage, mainly include PLC (Programmer Logic Controller), MCU (Micro Control Unit), and DSP (digital signal processor). As PLC has high reliability and strong anti-interference ability, it is usually used to directly control execution device to access a vehicle [2, 3, 5, and 6], but its operation ability is poor. Except powerful functions, MCU and DSP have a high-speed computing power, so they are used to complete the intelligent and large-scale control of a stereo garage [5, 6]. And only PLC is enough to control an unintelligent stereo-garage with a few parking spaces. However it is necessary that PLC together with MCU (or DSP) are used to construct the intelligent monitoring system for an intelligent stereo-garage with a large number of parking spaces, and an appropriate control strategy is used to effectively access vehicles so that to reduce waiting time during the peak of accessing vehicles [7, 8].

A stacker translation stereo garage and its PLC control system are presented in this paper. In order to shorten the access car waiting time, reduce the energy consumption, and increase work efficiency of the stereo garage, it is used to automatically access vehicles by queuing theory. 


\section{Overall Scheme of the Stacker Translation Stereo-garage}

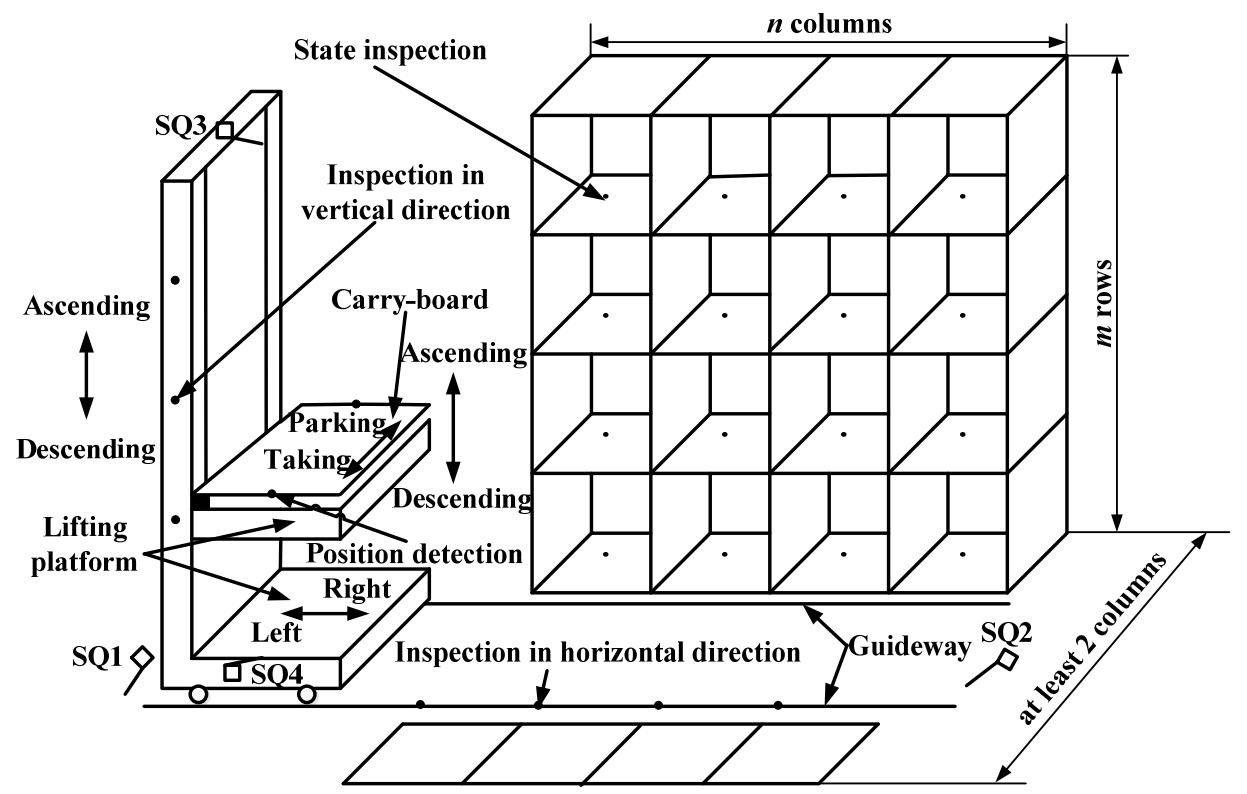

Fig. 1 Structure scheme of the stacker translation stereo garage

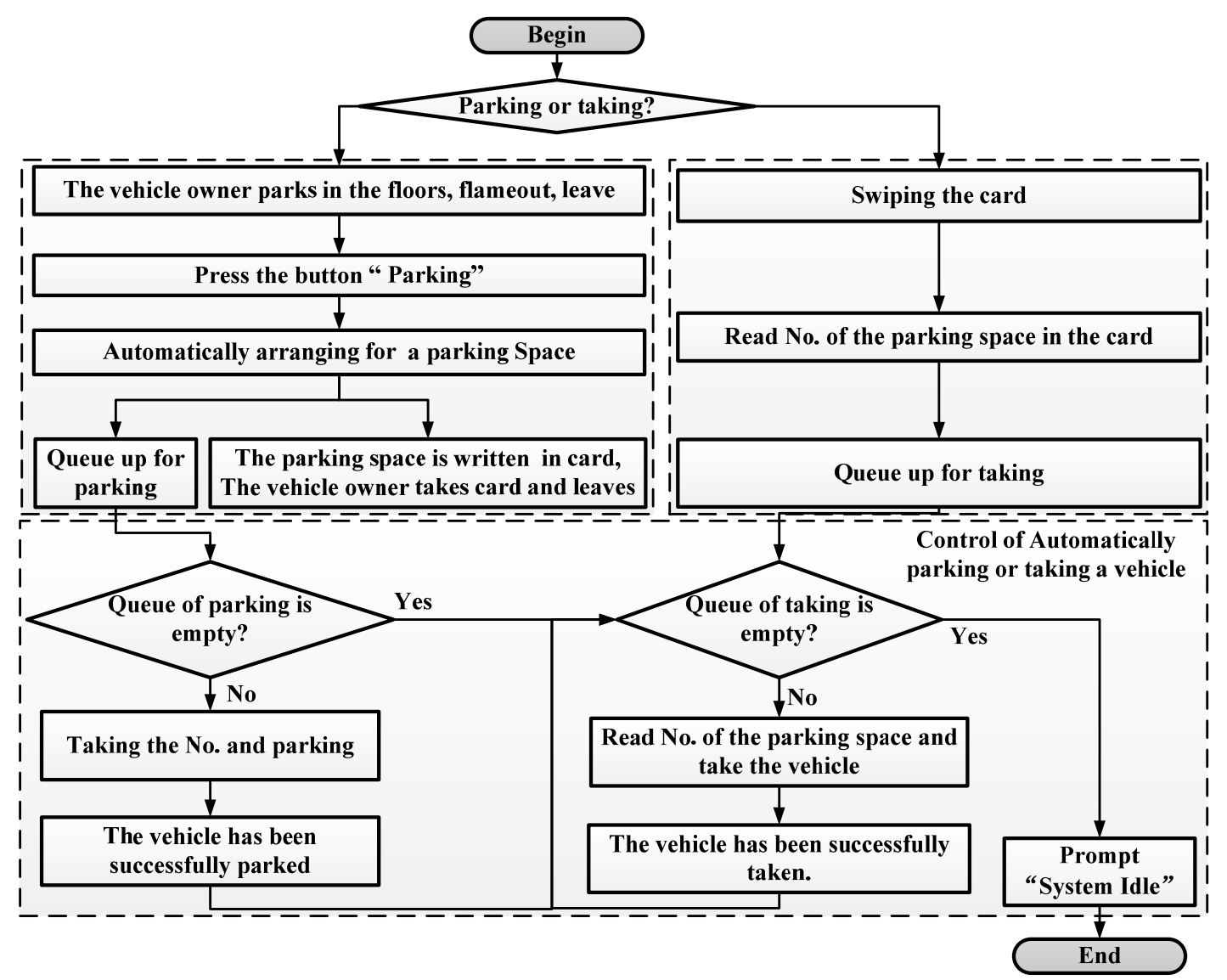

Fig 2 Automatically parking and taking flow of a vehicle

The structural scheme of the stacker translation stereo garage is showed in Figure 1. As shown in Fig. 1 , the garage has at least two columns which have m rows by n columns, and between any two columns there is a delivering vehicle which includes two parts, i.e. selection and access mechanism. The selection mechanism, which includes two mechanisms in horizontal and vertical direction, is used to select the parking space, and after selecting a parking space, the vehicle will be parked or took by the access mechanism. In order to automatically select the parking space, there are respectively four inspections in the horizontal and vertical direction. Two position detections are used to park or 
take a vehicle. The function of the limit switches SQ1-SQ4 is to ensure security when selecting the parking space. There is a state inspection in every parking space to judge whether a vehicle have already been parked in the parking space.

Based on the Queuing Theory, the automatically parking and taking flow of a vehicle shown in Figure 2 is proposed to reduce the waiting time. As shown in Fig. 2, when the system is in standby mode, the vehicle owner could choose "parking" or "taking" according to the prompt. If "parking", firstly the vehicle owner should park his vehicle in the right position in the floors, flame out and get off. And then he must been press the button "Parking", the system will automatically arrange for a parking space to park his vehicle and pop up a card which the No. of the parking space has been written in. Finally the system begins to park the vehicles by No. of the parking space in queue until all vehicles are parked in the garage. If "taking", firstly the vehicle owner should swipe the card, and then the system will automatically read No. in the card and takes the vehicle from the parking space.

\section{Analysis on Input and Output Electrical Appliances}

The input electrical appliances usually include motors and display. For $m=n=4$, only two columns, according to the structural scheme in Fig. 1 and control flow shown in Fig. 2, four motors and eights relays, as shown in Table 1 are required to realize automatically parking and taking flow. In order to know the running state of the translation motion stereo-garage, A two 8421 BCD code seven segment digital tube is used to display the parking space which has been selected to park or take a vehicle. Two indicator lights are used to the state of "Parking/Taking" and "Ready".

Table 1 Drive motor and its control electrical appliances

\begin{tabular}{cccccc}
\hline No. & Functions & & Motor & Forward & Backward \\
\hline 1 & \multirow{2}{*}{ selection mechanism } & Translation & Three-phase asynchronous motor & KM4 & KM3 \\
2 & & Lifting & Three-phase asynchronous motor & KM1 & KM2 \\
3 & \multirow{2}{*}{ Access mechanism } & Translation & Three-phase asynchronous motor & KM5 & KM6 \\
4 & & Lifting & Three-phase asynchronous motor & KM7 & KM8 \\
\hline
\end{tabular}

Table 2 Selection of sensors

\begin{tabular}{lcccc}
\hline No & Position & Quantit & Fuction \\
\hline 1 & Two side of carry-board & 2 & Determining whether the carry-board has reach the specified location \\
2 & In the parking space & 32 & Determing whether there is a vehicle in the parking space \\
3 & On the track & 4 & Column inspection \\
4 & On the column of hoisting appliance & 4 & Row inspection \\
5 & Bottom of the hoisting appliance & 1 & Initial position of the hoisting appliance \\
\hline
\end{tabular}

Table 3 I/O ports which are required for the garage of $m=n=4$, only two columns

\begin{tabular}{|c|c|c|c|}
\hline Name & Class & Quantity & Total \\
\hline Switcher/Control button/limit switch & & $4 / 12 / 8$ & \\
\hline Lifting inspection/Translation inspection & & $2 / 2$ & \\
\hline Senors in the parking space & Input & 32 & 69 \\
\hline Row inspection/Column inspection & & $4 / 4$ & \\
\hline Intial position senor & & 1 & \\
\hline Relays for motor control & Output & 8 & 19 \\
\hline Indicator lights for “parking/taking”/ seven segment digital tube & Output & $3 / 8$ & 19 \\
\hline
\end{tabular}

The output electrical appliances usually include function buttons and all kinds of signal detecting elements to realize automatically parking or taking. According the user requirements for the garage, 
the following function button are provide, such as mode selection switch, power button, start button, stop button, back button, manual directional control buttons, access button, and etc. According the requirement of the automatic control, the signal detecting elements which are required is shown in Table 2, especially, eight limit switches are employed to realize safety protection.

Above all, According to the number of sensors used in the control plan, quantity of limit switches, motor driving conditions, and etc., I/O ports which are required for the garage of $m=n=4$, only two columns, shown in Table 3. As shown in Table 3, the system needs 69 inputs and 19 outputs.

\section{PLC Control System for Translation Motion Stereo-garage}

The schematic diagram of PLC control system for translation motion stereo-garage ( $m=n=4$, only two columns) is shown in Figure 3. As shown in Fig. 3, the system needs 69 inputs and 19 outputs, and considering 3\% -4\% Remain, FX3U-80MR/DS base module and FX2NC-32EX extended module are selected. Furthermore, FX3U-232-BD communication module is used to link the card reader.

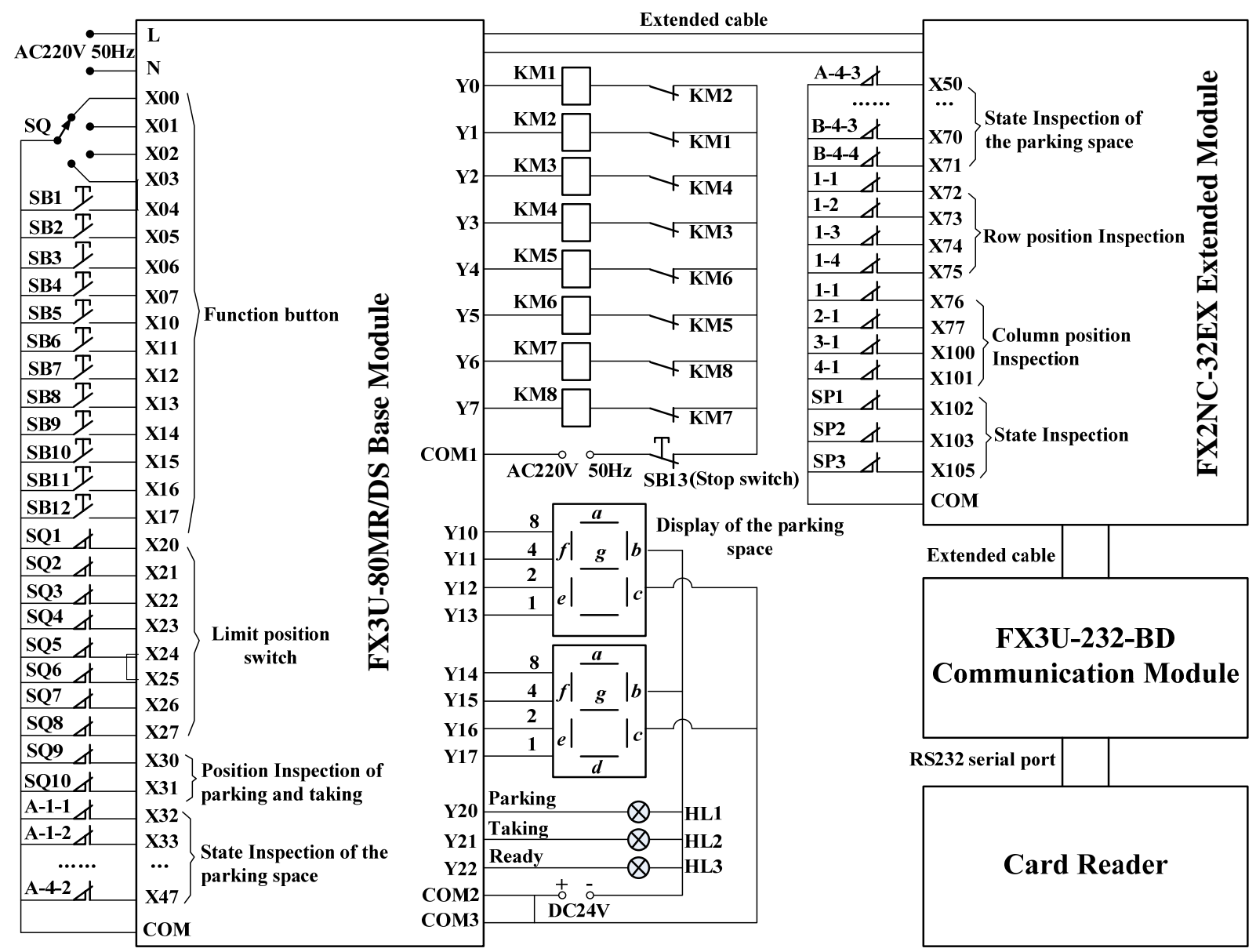

Fig. 3 Schematic diagram of PLC control system for Translation Motion Stereo-garage ( $m=n=4$, only two columns)

\section{Conclusions}

Compared with the traditional relay control circuit, PLC control has unique advantages in industrial environment applications, so PLC has a wide range of applications in the realization of logic control, sequence control, timing, counting and other aspects. Translation stereo garage control system is put forward in this paper to realize the three-dimensional garage startup control and stock car, the car control, single step control, manual control and parking control status display. So it is enough to satisfy the requirement of the stereo garage control conditions. Except that, it can not only save an area of space and construction cost, and but also realizes the full automation control and completely separating people and vehicles to ensure the safety of the people and vehicles. The system is well in 
the actual applications, and it has a certain reference value for the control system design of the other three-dimensional garage with different structural form.

\section{Acknowledgement}

This work was financially supported by Sichuan Aerospace College of Vocational Technology.

\section{References}

[1] LIANG Xiu-yin, DUAN Cheng-cai, LI Qin-Wei. Design of the laneway-stow-planar-typed solid garage structure and control system [J]. Manufacturing Automation, 2010, 32(2): 181-183.(in Chinese)

[2] WANG Bao-ming, CHA Man-li. Design of Monitoring System for Stereo Garage [J]. Control Engineering of China, 2007, 14(S0): 199-200. (in Chinese)

[3] Yi-Wei Liu. The Design of Control System of the Stereo Garage Based on PLC [J]. Science Technology and Engineering, 2011, 9(27): 6735-6737. (in Chinese)

[4] HE Yong-jun, YANG Cheng-chao, ZHOU Xue-hong et al. Structural Forms, Application and Development of Three-dimensional Garages [J]. Journal of Architecture and Civil Engineering, 2009, 26(4): 30-34. (in Chinese)

[5] TANG Yi-qing, TAN Shan-wen, TANG Yi-long. Mechanical Stereo Garage Controlled by the Single-chip [J], Mechanical Engineering \& Automation, 2006, (1): 31-33, 36. (in Chinese)

[6] ZHANG Yu-bin, WANG Wan-cheng, WANG Zhi-qin, et al. Design of Stockroom - Style Parking Control System Based on DSP [J]. Computer Measurement \& Control, 2013, 21(3): 648-650. (in Chinese)

[7] LI Jian-feng, DUAN Wen-jun, FANG Bin,et al. Three-dimensional Garage Scheduling Optimization Based on Improved Genetic Algorithm [J]. Control Engineering of China, 2010, 17(5):658-661. (in Chinese)

[8] MA Chang-cheng. Achieving the Dispatching of Group Control Stereoscopic Garage Based on Improved Ant Colony Algorithm [J]. Computer Measurement \& Control, 2014, 22(3): 764-768. (in Chinese) 